\title{
Effect of Isoniazid on Biosynthesis in Mycobacterium tuberculosis var. bovis $\mathrm{BCG}$
}

\author{
BY J. W. T. WIMPENNY* \\ Department of Bacteriology, Guy's Hospital Medical School, \\ London, S.E. 1
}

(Accepted for publication 25 January 1967)

\begin{abstract}
SUMMARY
Radioactive incorporation techniques have been employed to investigate the effect of isonicotinic acid hydrazide (INH) on biosynthetic reactions in Mycobacterium tuberculosis var. bovis BCG. INH has no measurable effect on incorporation of ${ }^{32} \mathrm{P}$ phosphate, ${ }^{35} \mathrm{~S}$ sulphate or ${ }^{14} \mathrm{C}$ glycine into whole cells, although it inhibits by $50 \%$ the incorporation of ${ }^{{ }^{14}} \mathrm{C}$ acetate. Incorporation of ${ }^{32} \mathrm{P}$ into trichloracetic acid (TCA) insoluble components of supernatant solutions from centrifuged disrupted bacteria appears to be inhibited soon after the cells are exposed to INH. Similar experiments with ${ }^{35} \mathrm{~S}$ show a lag of $30-40 \mathrm{hr}$ before incorporation is influenced by the drug. Chemical fractionation of organisms grown in the presence of ${ }^{32} \mathrm{P}$ show that the major effect of INH is exerted on incorporation into the ribonucleic acid fraction.
\end{abstract}

\section{INTRODUCTION}

In the fourteen years since isoniazid (INH) was first described (Fox, 1951) much research has been carried out to discover its mode of action and specificity, but the answer to these questions remains unclear. It is known that INH begins to be bactericidal to mycobacteria after a lag of one to two generation times (Middlebrook, 1952; Barclay, Ebert \& Koch-Weser, 1953). In parallel with the decline in viability there was a diminution in acid-fast staining and neotetrazolium reducing activity (Koch-Weser, Barclay \& Ebert, 1955). Schaefer (1954) demonstrated that INH is only active against tubercle bacilli when they were actively dividing and metabolizing in the presence of an energy source. These findings suggest that INH inhibits some aspect of biosynthetic metabolism and that the expression of this lesion is delayed. For example, the drug might inhibit the formation of an essential metabolite enough of which remains to permit growth for about one more generation. A number of enzyme systems have been shown to be affected by INH, among them those requiring pyridoxal phosphate as a co-factor, some involved in nicotinamide adenine dinucleotide metabolism, some amine oxidase enzymes, and catalase and peroxidase from various sources. However, it cannot yet be said that the antibiotic action of INH is definitely related to any of these systems. Many of the proposed sites of action have been reviewed by KrügerThiemer (1958). As INH is only active in growing bacteria it seemed that a study of the effect of this drug on biosynthetic reactions might throw light on the mode of action of INH.

\footnotetext{
* Present address: Department of Microbiology, University College, Cardiff.
} 


\section{METHODS}

Organism and media. The Copenhagen strain of Mycobacterium tuberculosis var. bovis $\mathrm{BCG}$, sensitive to $0 \cdot 05-0 \cdot 1 \mu \mathrm{g}$. INH/ml. was obtained from Glaxo Laboratories Ltd., Greenford, Middlesex, through the kindness of Dr J. P. Ungar.

The strain was maintained by monthly subcultivation on Lowenstein-Jensen slopes. For use it was subcultured three times at intervals of 8 days in Dubos fluid medium (Dubos \& Davis, 1946) containing $0.3 \%$ bovine albumen and incubated at $37^{\circ}$. Synthetic AFMR medium (Aldridge, Felton, Muchmore \& Ramsay, 1959) containing glucose, ammonium chloride, salts and Tween 80 , was dispensed in $100 \mathrm{ml}$. quantities in Roux bottles which were inoculated with $1.0 \mathrm{ml}$. of the third Dubos culture and incubated horizontally at $37^{\circ}$ for $14-21$ days.

\section{Radioactive tracer techniques}

The following isotopes were obtained from the Radiochemical Centre Amersham, Bucks: ${ }^{35} \mathrm{~S}$ as sulphate, ${ }^{32} \mathrm{P}$ as orthophosphate, acetate- $1-{ }^{14} \mathrm{C}(2 \mathrm{mc} / \mathrm{mmole})$ and glycine- ${ }^{14} \mathrm{C}(\mathrm{U})(2 \mathrm{mc} / \mathrm{mmole})$. Diluted solutions of all isotopes in distilled water were sterilized by autoclaving at $120^{\circ}$ for $10 \mathrm{~min}$. Samples containing ${ }^{14} \mathrm{C}$ and ${ }^{35} \mathrm{~S}$ were counted on nickel planchettes with an end-window Geiger tube, either at infinite thinness or corrected for self-absorption against standard self-absorption curves. ${ }^{32} \mathbf{P}$ was estimated in the same way or in a liquid counting tube containing $10 \mathrm{ml}$. solution.

Incorporation into whole bacteria. For experiments on incorporation of ${ }^{14} \mathrm{C}$ glycine, ${ }^{14} \mathrm{C}$ acetate and ${ }^{35} \mathrm{~S}$ into whole bacteria, three 18 -day cultures in AFMR medium received sterile INH to a final concentration of $10 \mu \mathrm{g} . / \mathrm{ml}$. and three control cultures were treated with a similar quantity of sterile distilled water. Each group of six then received either ${ }^{14} \mathrm{C}$ glycine $(5 \mu \mathrm{c}),{ }^{14} \mathrm{C}$ acetate $(0.45 \mu \mathrm{c})$ or ${ }^{35} \mathrm{~S}$ sulphate $(10 \mu \mathrm{c})$. At intervals during further incubation at $37^{\circ}, 6 \mathrm{ml}$. samples from 2 of every test and 2 of every control culture were withdrawn aseptically. The organisms in each sample were washed, by centrifugation, in, successively, $0 \cdot 1 \%$ solution of Triton WR 1339 (a dispersing agent) in $0 \cdot 1 \mathrm{M}$-phosphate buffer ( $\mathrm{pH} \mathrm{6.8),} \mathrm{Triton-phosphate} \mathrm{buffer} \mathrm{con-}$ taining $0.1 \mathrm{M}$-non-radioactive acetate, glycine or sulphate and, finally, in Tritonphosphate buffer; their specific activities were then determined.

Incorporation of ${ }^{32} \mathrm{P}$ orthophosphate was followed in a similar fashion in 18-day cultures of BCG grown on AFMR medium. To each of 14 bottles was added $10 \mu \mathrm{C}$ of ${ }^{32} \mathrm{P}$ orthophosphate. Half of the bottles also received sterile INH to $10 \mu \mathrm{g} . / \mathrm{ml}$. final concentration. One test and one control culture were harvested at various times by centrifugation. The organisms were washed successively in $0.1 \%$ Triton distilled water, $0.1 \%$ Triton in $0.1 \mathrm{M}$-phosphate buffer ( $\mathrm{pH} 6.8$ ), and finally $0.02 \%$ Triton distilled water before their radioactivity was assayed.

Incorporation into trichloracetic acid (TCA) insoluble compounds. Each 18-day culture on AFMR medium was given $10 \mu \mathrm{C}{ }^{32} \mathrm{P}$ orthophosphate solution and $10 \mu \mathrm{C}$ of ${ }^{35} \mathrm{~S}$ sulphate solution and isoniazid was added to half of the bottles. The organisms were harvested by centrifugation and were washed by centrifugation in, successively, Triton-water and Triton- $0 \cdot 1 \mathrm{M}$-phosphate buffer ( $\mathrm{pH} 6 \cdot 8$ ) containing non-radioactive sulphate. The organisms were finally suspended in $25 \mathrm{ml} .0 .02 \%$ Triton water and broken in the extrusion press (Milner, Lawrence \& French, 1950). The broken sus- 
pension was centrifuged at $30,000 \mathrm{~g}$ for $20 \mathrm{~min}$. in an MSE-' 17 ' refrigerated centrifuge and measured volumes of the opalescent supernatant were treated with an equal volume of chilled $10 \%(\mathrm{w} / \mathrm{v}) \mathrm{TCA}$ and held at $4^{\circ}$ for $30 \mathrm{~min}$. The precipitate was collected by centrifugation and washed in, successively, $5 \%$ TCA containing $1 \%$ nonradioactive phosphate and sulphate, $5 \%$ TCA and $1 \%$ acetic acid. The washed pellets were transferred to weighed nickel planchettes, dried, reweighed and counted with and without an aluminium screen to allow separate estimates of ${ }^{32} \mathrm{P}$ and ${ }^{35} \mathrm{~S}$.

Incorporation into various cell fractions. To obtain information on the effect of INH on incorporation of radioactive phosphate into various cell fractions, broken organisms were fractionated by the method of Winder \& Denneny (1957) or by that of Schmidt \& Thannhauser (1945). Using the Winder \& Denneny fractionation scheme, organisms were grown, harvested, washed and broken as for experiments measuring incorporation into TCA insoluble components.

In experiments using the Schmidt-Thannhauser procedure, after normal growth on AFMR medium for 18 days, the organisms were harvested and resuspended aseptically in phosphate-free medium ( $\mathrm{pH} 7.0$ ). Each culture received $2 \mu \mathrm{g}$. $/ \mathrm{ml}$. INH or sterile water in the first experiment. Each culture in the second experiment was treated with either $20 \mu \mathrm{g}$. $/ \mathrm{ml}$. streptomycin (SM) or $1 \mu \mathrm{g}$. $/ \mathrm{ml}$. INH or sterile water. There was no significant change in $\mathrm{pH}$ during the course of each experiment in any culture vessel. Organisms from each experiment were tested for bacterial contamination and were harvested, washed and broken as described above.

Analytical methods. Total phosphorus was measured after digesting the sample in perchloric acid by the technique of Strickland, Thompson \& Webster (1956). Free phosphate was measured directly on material containing $0 \cdot 1-1 \cdot 0 \mu \mathrm{M}$-phosphorus by the method of Fiske \& SubbaRow (1925). Acid labile phosphorus was measured similarly after hydrolysis of the sample in $\mathrm{N}-\mathrm{HCl}$ for seven minutes at $100^{\circ}$.

Chromatography. Two-dimensional chromatography on products of nucleic acid hydrolysis was performed either in the solvent system described by Roberts et al. (1955) or in the system devised by Dorough \& Seaton (1954). Roberts et al. used 70\% tertiary butanol in $0.8 \mathrm{~N}-\mathrm{HCl}$ in the first direction and secondary butanol + water + formic acid $(70+20+10)$ in the second direction. Radio-autographs were prepared on Ilford X-ray paper and contact prints were made of the chromatograms on Kodak reflex document paper, using an ultraviolet lamp with a Chance OX 7 filter.

The spots, located as described above, were cut from the paper and extracted with a small quantity of $0 \cdot 1 \mathrm{~N}-\mathrm{HCl}$. The radioactivity of these solutions was estimated by making up to $10 \mathrm{ml}$. and counting in a liquid Geiger-counter tube. A paper blank from each chromatogram was treated in the same way. The absorbancy of the eluates at 250,260 , and $280 \mathrm{~m} \mu$ was measured spectrophotometrically. The specific activity of each extract was expressed as counts/min./O.D. unit at $260 \mathrm{~m} \mu$ or in terms of the o.D. at $260 \mathrm{~m} \mu$ of the guanine spot on each chromatogram. The ratios of absorbancy at 250-260 $\mathrm{m} \mu$ and $280-260 \mathrm{~m} \mu$, together with the location of the spot on the paper, were used to assist in establishing the identity of each spot.

The solvents employed by Dorough \& Seaton (1954) were $n$-butanol+acetic acid + water $(8+8+2)$ and acetone $+n$-butanol + water $(8+1+1)$ in the first direction followed by isopropanol + ammonium sulphate + water $(79+2+19)$ in the second direction. The chromatograms were run on Whatman no. 1 paper. Spots were located by ultraviolet photography. Quantitative estimations were similar to those described 
above. The activity was eluted from blank and test spot by macerating the paper in $0.1 \mathrm{~N}-\mathrm{HCl}$ and removing the paper fibres by centrifugation. These were washed and the supernatants combined and made up to $10 \mathrm{ml}$. for counting and measurement of ultraviolet absorbance. Blank deductions from each spot were corrected for the size of the spot using the weight of the paper as criteria of size. Specific activities were determined as described above.

\section{RESULTS}

\section{Incorporation into whole cells}

Incorporation of ${ }^{35} \mathrm{~S}$ sulphate, ${ }^{32} \mathrm{P}$ orthophosphate and ${ }^{14} \mathrm{C}$ glycine was not affected significantly by $10 \mu \mathrm{g} . / \mathrm{ml}$. INH during $100 \mathrm{hr}$ exposure in the sulphate and glycine experiments, and $50 \mathrm{hr}$ exposure in the orthophosphate experiment. However, ${ }^{14} \mathrm{C}$ acetate incorporation was inhibited to about $50 \%$ of the control level by the same concentration of INH (Fig. 1). It is difficult to interpret the inhibition of acetate due to INH as it appeared long before growth of the organism was itself inhibited. It seems possible that this inhibition is not related to the bactericidal action of INH, since acetate is not needed for growth.

\section{Incorporation into TCA insoluble cytoplasmic components}

The effect of INH on the incorporation of ${ }^{32} \mathrm{P}$ orthophosphate and ${ }^{35} \mathrm{~S}$ sulphate into TCA insoluble components of the cell-free fraction of disrupted BCG was next examined. The TCA precipitate contained the cytoplasmic protein and much of the nucleic acid components. Incorporation of ${ }^{35} \mathrm{~S}$ sulphate and ${ }^{32} \mathrm{P}$ orthophosphate into these components of BCG was measured in preliminary experiments and it appeared that INH significantly inhibited ${ }^{32} \mathrm{P}$ incorporation immediately and inhibited ${ }^{35} \mathrm{~S}$ sulphate incorporation after a lag period of $30-40 \mathrm{hr}$. This was investigated using both tracers in the same experiment; 18-day cultures of BCG were employed. Each vessel received either $10 \mu \mathrm{g} . / \mathrm{ml}$. INH or distilled water. In addition, $10 \mu \mathrm{C}{ }^{32} \mathrm{P}$ orthophosphate and $10 \mu \mathrm{C}{ }^{35} \mathrm{~S}$ sulphate were added. A test and control culture were harvested at various times up to $140 \mathrm{hr}$. Since there was a certain amount of scatter in results from vessel to vessel, the results have been smoothed by plotting a moving average (Fig. 2). While incorporation of ${ }^{35} \mathrm{~S}$ sulphate was hardly affected before $30-40 \mathrm{hr}$ in the presence of $\mathrm{INH}$, the drug appears to inhibit ${ }^{32} \mathrm{P}$ orthophosphate incorporation considerably as soon as the organism was exposed to INH. If ${ }^{35} \mathrm{~S}$ incorporation is a measure of protein synthesis and ${ }^{32} \mathrm{P}$ incorporation is a measure of nucleic acid synthesis, it is possible that INH inhibits some aspect of nucleic acid synthesis soon after the organism is exposed to the drug and that this inhibition is followed by a cessation of protein synthesis after 30-40 hr. However, the fractionation procedure does not rule out the possibility of incorporation of either tracer into other TCA precipitable components which might be present in the supernatant; other fractionation procedures were therefore tested.

\section{Fractionation by the Winder \& Denneny method}

The affect of INH on ${ }^{32} \mathrm{P}$ incorporation was further studied. After incubation for $40 \mathrm{hr}$ with INH and ${ }^{32} \mathrm{P}$ phosphate, organisms were broken in the French press and subsequently fractionated as described by Winder \& Denneny (1957). This fractionation procedure consists in extracting phospholipids with ethanol and ether + ethanol, followed by selective hydrolysis of ribonucleic acid (RNA), desoxyribonucleic acid 
(DNA) and polyphosphate with $5 \%$ TCA at room temperature. The specific activity as counts $/ \mathrm{min} . / \mu \mathrm{g}$. $\mathrm{P}$ was determined in duplicate for each fraction. The results are set out in histogram form (Fig. 3). It is evident that INH does not significantly inhibit incorporation of ${ }^{32} \mathrm{P}$ into phospholipids, phosphoprotein or inorganic polyphosphate.

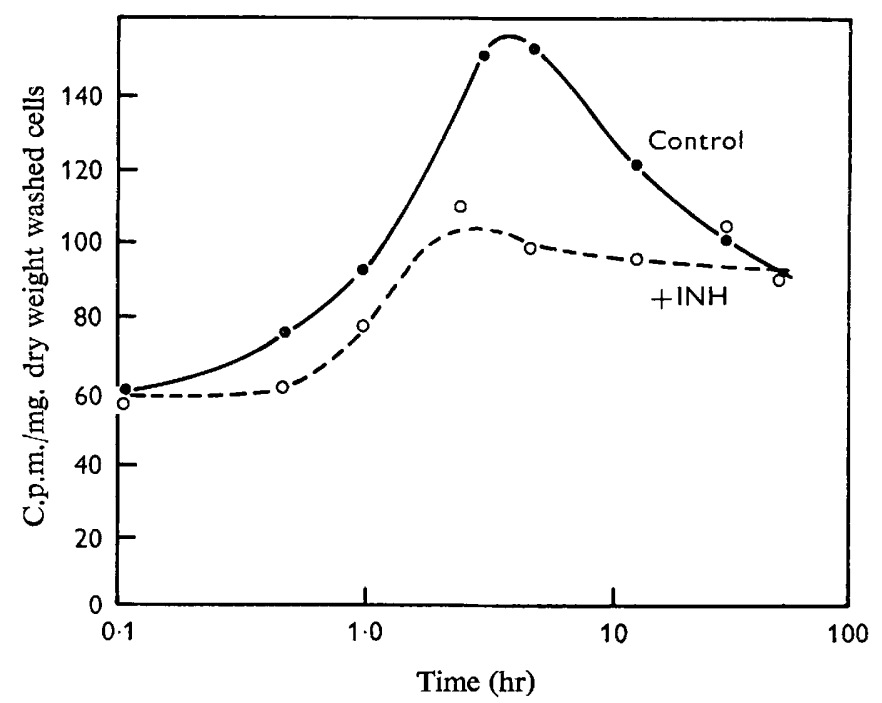

Fig. 1. The effect of INH on ${ }^{14} \mathrm{C}$ acetate incorporation into $\mathrm{INH}$-sensitive BCG. Test and control cultures received $0.45 \mu \mathrm{C}{ }^{14} \mathrm{C}$ acetate at time zero. At the same time test cultures were treated with $10 \mu \mathrm{g} . / \mathrm{ml}$. INH.

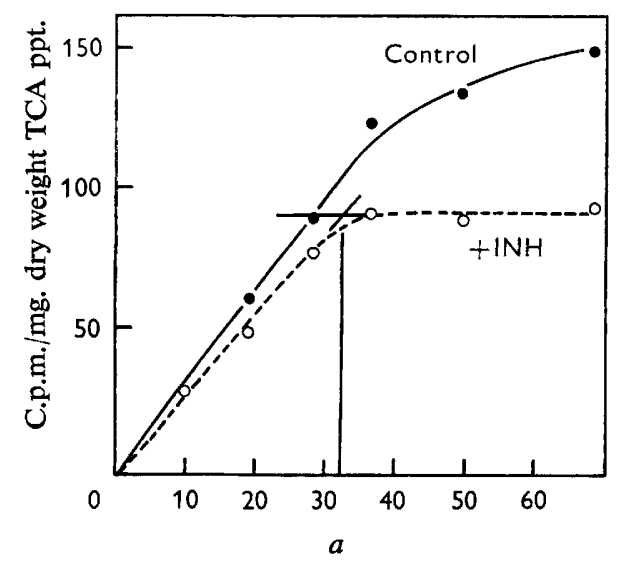

Time (hr)

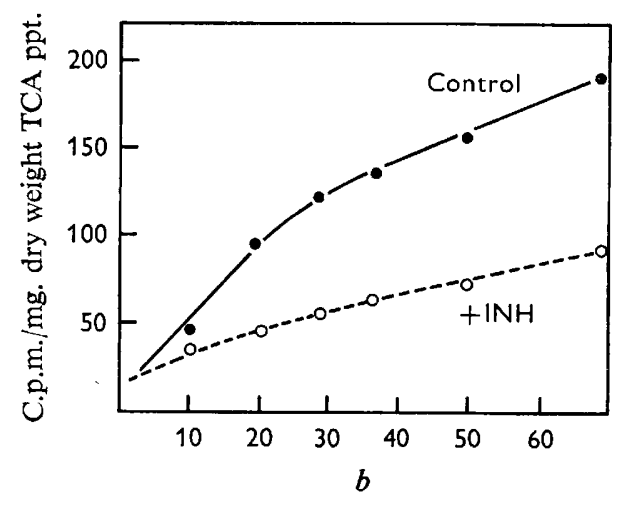

Time (hr)

Fig. 2. The effect of $\mathrm{INH}$ on ${ }^{32} \mathrm{P}$ and ${ }^{35} \mathrm{~S}$ incorporation into TCA precipitable cytoplasmic components of INH-sensitive BCG. At time zero all cultures received $10 \mu \mathrm{C}{ }^{35} \mathrm{~S}$ sulphate and $10 \mu \mathrm{C}^{32} \mathrm{P}$ orthophosphate. In addition test cultures were exposed to $10 \mu \mathrm{g} . / \mathrm{ml}$. $\mathrm{NNH}$. The data have been plotted as a moving average. (a) Incorporation of ${ }^{35} \mathrm{~S}$. (b) Incorporation of ${ }^{32} \mathrm{P}$.

There is no detectable effect on fractions $R_{1}$ and $R_{2}$ which contain RNA, polyphosphate, and DNA purines. Any effect on nucleic acid synthesis in these fractions will however be obscured by the large excess of polyphosphate in each of these fractions 
whose biosynthesis is not affected. There appears to be some reduction in specific activity in the TCA soluble component and in fraction D containing DNA or (mainly) apurinic acid and polyphosphate, but it proved impossible to determine the specific activity of nucleic acid components.

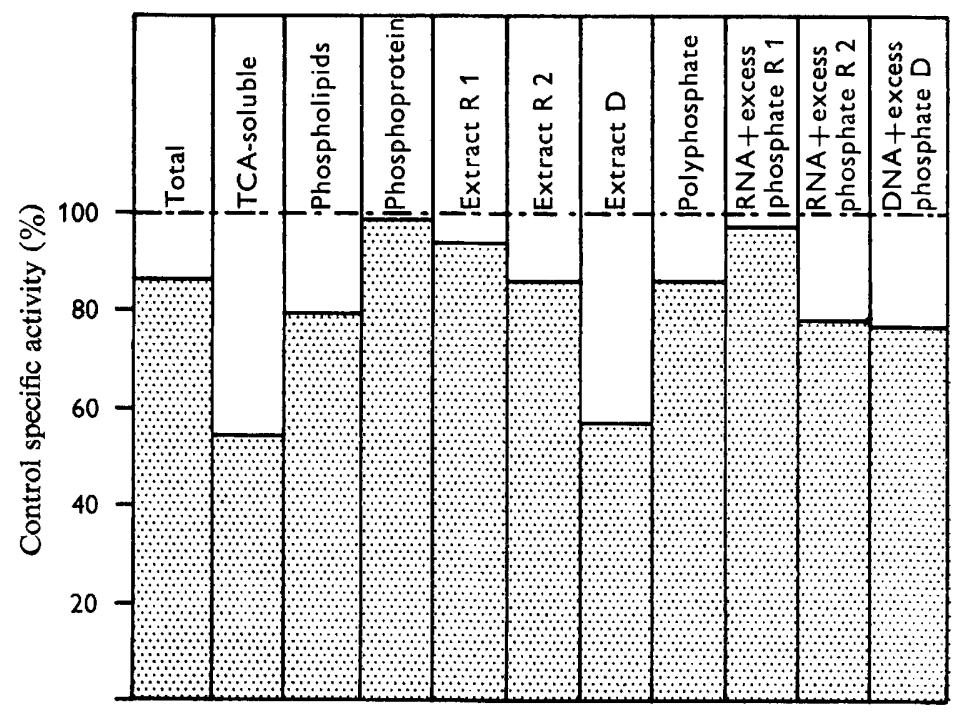

Fig. 3. The effect of INH on the specific activity of ${ }^{32} \mathrm{P}$-phosphorus-containing fractions. Test and control cultures received $10 \mu \mathrm{C}$ sterile ${ }^{32} \mathrm{P}$ orthophosphate. Test cultures were treated with $1.0 \mu \mathrm{g} . / \mathrm{ml}$. INH. After incubating at $37^{\circ}$ for $40 \mathrm{hr}$, cells were fractionated according to the method of Winder \& Denneny (1957). Fractions referred to in the histogram are those described by the above authors.

\section{Fractionation by the Schmidt-Thannhauser method}

INH-sensitive BCG was grown on AFMR medium for 16 days as usual, harvested under sterile conditions and resuspended in $100 \mathrm{ml}$. of phosphate-free AFMR medium at $\mathrm{pH} 7 \cdot 0$, so that each suspension contained the growth from $1 \frac{1}{2}$ Roux-bottle cultures. To each bottle was added $100 \mu \mathrm{C}{ }^{32} \mathrm{P}$ orthophosphate. Test cultures received sterile INH to $2 \mu \mathrm{g}$./ml. or an equivalent volume of sterile distilled water. All bottles were incubated at $37^{\circ}$ for $68 \mathrm{hr}$. Each culture was checked for bacterial contamination and $\mathrm{pH}$ before harvesting. There was no detectable change in the $\mathrm{pH}$ of each culture.

${ }^{32} \mathrm{P}$ uptake was therefore studied in cells which were then washed, broken and treated according to Schmidt \& Thannhauser (1945). In the first experiment chromatographic analysis of the nucleic acid derivatives was carried out using the solvent system of Roberts et al. (1955). The results are presented as a histogram (Fig. 4). It can be seen that while INH had very little effect on ${ }^{32} \mathrm{P}$ incorporation into either whole cells, acid soluble material, phosphoprotein or phospholipid it had a profound effect on the RNA fraction. Three ribonucleotides, guanylic acid, uridylic acid and cytidylic acid were tentatively identified by their ultraviolet absorption characteristics and by their position on each chromatogram. The specific activity of each of these ribonucleotides in organisms exposed to $2 \mu \mathrm{g}$. INH/ml. for $68 \mathrm{hr}$ was $25 \%$ of the control activity, the greatest inhibition attributable to INH so far reported. It proved difficult 
to obtain much DNA material and the products of acid hydrolysis of this fraction could not be identified. Although there is no agreement between the specific activity of each of the three spots (labelled X, Y and Z) isolated from the hydrolysed DNA fraction, their activities are all lower than the whole cell specific activity. It is probable that incorporation of ${ }^{32} \mathrm{P}$ into DNA is inhibited although it is impossible to decide in which order (if any) nucleic acid synthesis is affected by INH.

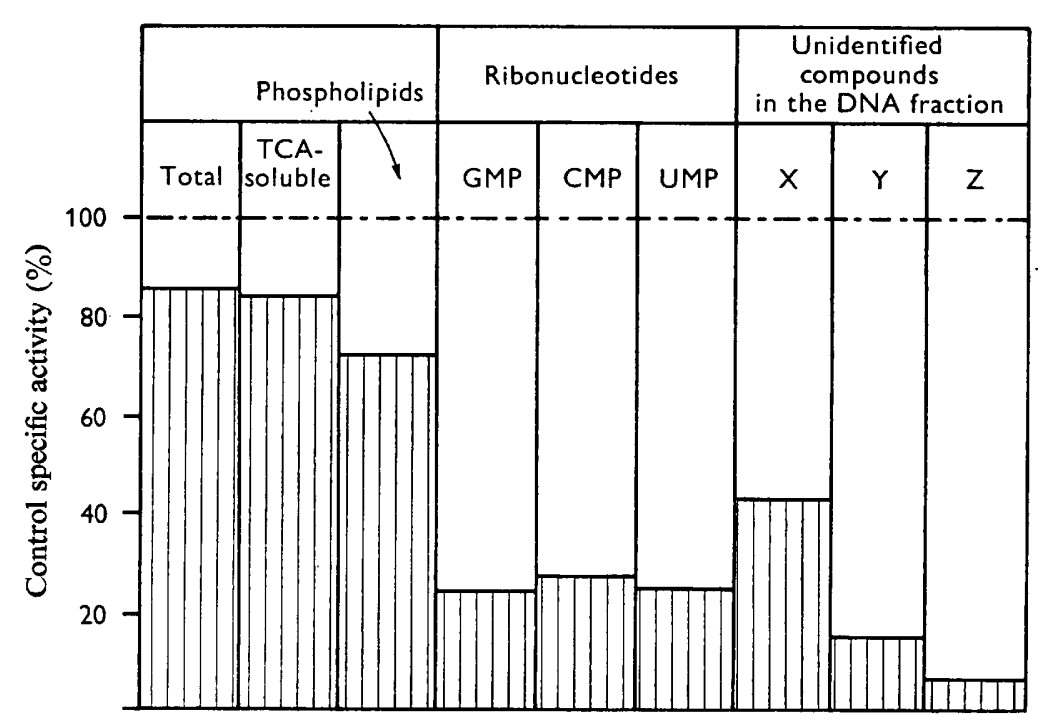

Fig. 4. The effect of INH on the specific activity of ${ }^{32} \mathrm{P}$-phosphorus-containing fractions. Sixteen-day-old cells were washed and suspended in a phosphate-free medium. Test and control cultures received $100 \mu \mathrm{C}{ }^{32} \mathrm{P}$ orthophosphate. Test cultures were treated with $2 \mu \mathrm{g}$. / ml. INH. After $68 \mathrm{hr}$ at $37^{\circ}$ cells were fractionated according to the method of Schmidt \& Thannhauser (1945).

This experiment was repeated and the effect of streptomycin (SM) contrasted with the effect of INH. It is known that while streptomycin exercises an immediate growthinhibitory effect, INH acts only slowly after a lag period of 1-2 generation times (Koch-Weser et al. 1955). Organisms were fractionated as already described except that chromatograms of nucleic acid derivatives were run in the Dorough \& Seaton (1954) solvent system. The results (Fig. 5) show that streptomycin inhibited incorporation of ${ }^{32} \mathrm{P}$ into all fractions tested. Incorporation into ribonucleotides was more reduced than in other fractions. However, in contrast to the effect of streptomycin, INH affected only the ribonucleotide fraction. In this experiment the specific activities in the control set appear to be low, but the relative order of inhibition in the treated sets is not affected.

\section{DISCUSSION}

The first experiments on the effects of INH on the incorporation of ${ }^{14} \mathrm{C}$ glycine, ${ }^{14} \mathrm{C}$ acetate, ${ }^{35} \mathrm{~S}$ sulphate and ${ }^{32} \mathrm{P}$ phosphate into washed whole $\mathrm{BCG}$ organisms showed that, with the exception of incorporation of ${ }^{14} \mathrm{C}$ acetate, there was no significant change in the specific activity of INH-treated and control organisms. The three metabolites 
glycine, sulphate and phosphate between them provide an indicator for the synthesis of most chemical fractions in mycobacteria. Hence it is probable that the site of action of INH is directed to a specific metabolic reaction, inhibition of which will have no immediate effect on overall biosynthesis. These results confirm the findings of several groups of workers on the effect of INH on the growth of mycobacteria. For example, it has been shown that growth of mycobacteria is inhibited only after a latent period of 1-2 generation times (Barclay et al. 1953; Schaefer, 1954). Mackaness \& Smith (1953) have also shown that INH inhibits a specific biosynthetic reaction and that the expression of this inhibition occurs after a considerable delay.

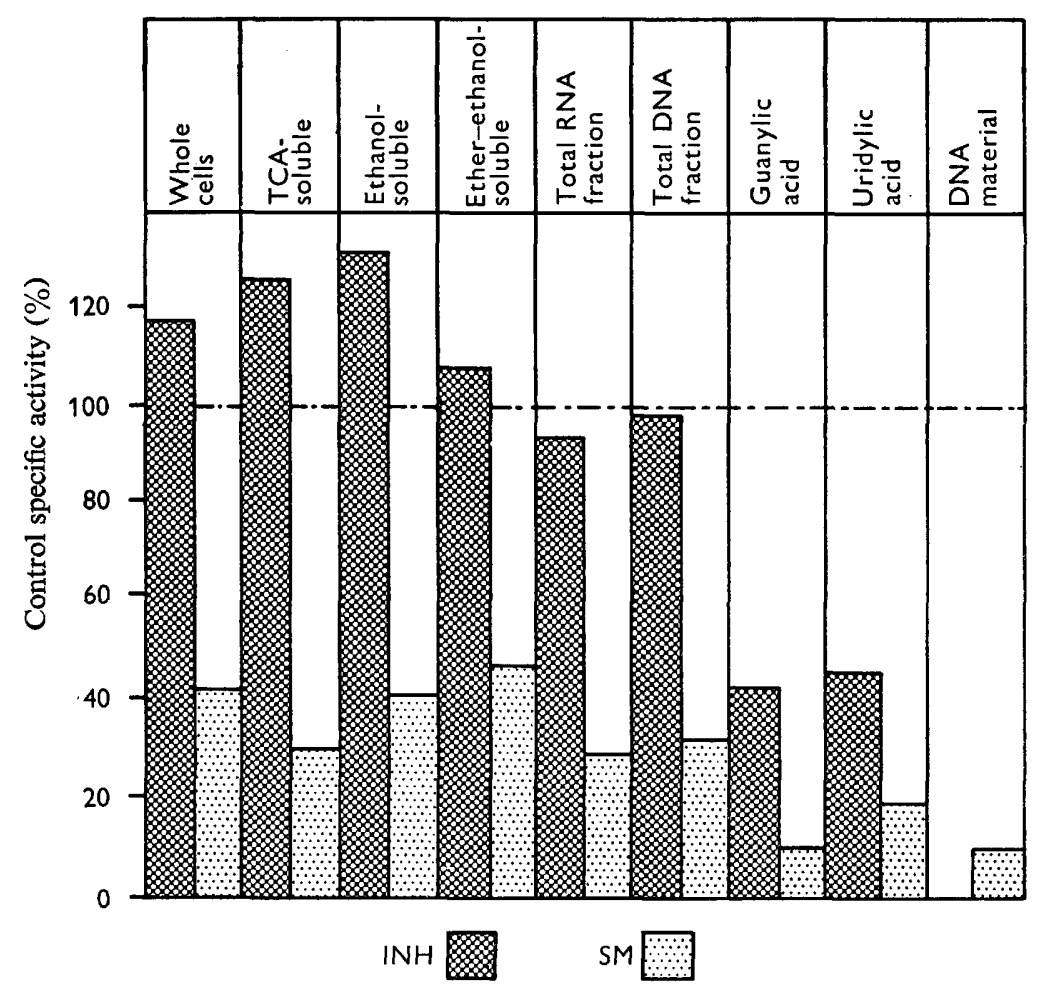

Fig. 5. The effect of INH and streptomycin (SM) on the specific activity of ${ }^{32} \mathrm{P}$-phosphoruscontaining fractions. Cells were treated as described for Fig. 4 with the exception that test cultures received either $20 \mu \mathrm{g} . / \mathrm{ml}$. SM or $1.0 \mu \mathrm{g} . / \mathrm{ml}$. INH.

With ${ }^{14} \mathrm{C}$ acetate the effect of INH was considerable. It was observed that during the first few hours of acetate fixation INH inhibits uptake by about $50 \%$. These results confirm the work of Meadow (1956) and Meadow \& Knox (1956) who demonstrated that oxidation of acetate by washed cells of Mycobacterium smegmatis and BCG was inhibited by INH to $50 \%$ of the control level. They concluded that an oxidation reaction within the mycobacterial cell was inhibited by the drug. This inhibition appeared to take place at widely differing INH concentrations although the amount of inhibition was always in the region of $50 \%$. The easiest interpretation of the data of these workers in the light of results with radioactive acetate is that INH inhibits not the oxidation but the uptake of the substrate. However, it is not easy to establish 
the relationship of the effect to the antibiotic action of INH, as this inhibition appears to occur at once in the presence of $\mathrm{INH}$ and acetate is not necessary for the growth of these organisms.

Incorporation of ${ }^{35} \mathrm{~S}$ sulphate into TCA-insoluble cytoplasmic components of BCG was not affected by INH over the first $30-40 \mathrm{hr}$; it then ceased completely. On the other hand, incorporation of ${ }^{32} \mathrm{P}$ orthophosphate into the same material was very greatly inhibited by INH as soon as the organisms were exposed to the drug. One explanation of these results seems to be that the delayed inhibition with ${ }^{35} \mathrm{~S}$ sulphate is a consequence of the effect observed with ${ }^{32} \mathrm{P}$ phosphate. If the inhibited portion of the phosphate-containing TCA-insoluble fraction is nucleic acid and if the sulphatecontaining component of the same fraction is protein it appears probable that INH inhibits some aspect of nucleic acid synthesis with the result that after a day protein synthesis ceases.

It was important to decide which phosphate compound was inhibited. The Winder \& Denneny fractionations showed that INH had no significant effect on phosphate incorporation into several components, including polyphosphate, phospholipid and residual phosphoprotein. This procedure did not show the effect of INH on nucleic acid synthesis. The Schmidt-Thannhauser fractionation showed that INH had little effect on the specific activity of ${ }^{32} \mathrm{P}$ in phospholipids, TCA-soluble components and whole cells. However, a great reduction was noted with ribonucleotide and the products of hydrolysis of DNA.

A similar experiment using INH and streptomycin as a second control showed that in contrast to the action of INH, streptomycin inhibited biosynthesis of every component to $30-40 \%$ of the control level although nucleic acid synthesis was affected even more. These findings are consistent with the results obtained by Barclay, Ebert \& Koch-Weser (1953) and Mackaness \& Smith (1953), who showed that INH inhibits growth of tubercle bacilli after a latent period corresponding to 1-2 generation times, whereas the bactericidal effect of streptomycin is immediate.

It is reasonable to conclude that INH first blocks some biosynthetic reaction which results in a cessation of nucleic acid synthesis. It is, of course, impossible to say that nucleic acid synthesis is the direct site of action of INH, although it is the earliest detectable effect of INH on the biosynthetic mechanisms in BCG reported so far. Following the blockage in nucleic acid synthesis, protein synthesis is inhibited, although this manifests itself after a lag period of $30-35 \mathrm{hr}$, which is similar to the delay in growth inhibition reported by the workers mentioned above. Finally, as a result of the cessation of protein synthesis, the synthesis of other cellular components is slowly affected as the concentration of most biosynthetic enzymes is reduced, either because they are diluted out or because they are broken down in the cell.

The results reported in this paper constitute part of a thesis presented to the University of London in 1962. Since this time the observation that INH inhibits some aspect of nucleic acid synthesis has been ably confirmed by Tsukamura \& Mizuno (1962) and Gangadharam, Harold \& Schaefer (1963) who used different analytical methods.

It is a pleasure to thank Professor R. Knox for his helpful suggestions and encouragement. This work was supported by a research grant from Guy's Hospital Endowment fund. 


\section{REFERENCES}

Aldridge, C., Felton, F. G., Muchmore, H. G. \& Ramsay, H. H. (1959). A new liquid synthetic medium for the cultivation of Mycobacterium species. Am. Rev. resp. Dis. 80, 267.

Barclay, W. R., Ebert, R. H. \& KoCH-WeSER, D. (1953). Mode of action of isoniazid. Am. Rev. Tuberc. 67, 490.

Dorough, G. D. \& Seaton, D. L. (1954). A method for the extraction and assay of nucleic acid fragments in tissues. J. Am. chem. Soc. 76, 2873.

Dubos, R. J. \& Davis, B. D. (1946). Factors affecting the growth of tubercle bacilli in liquid media. J. exp. Med. 83, 409.

Fiske, C. \& SubbaRow, Y. (1925). The colorimetric determination of phosphorus. J. biol. Chem. 66, 375 .

Fox, H. H. (1951). Synthetic tuberculostats. Isonicotinaldehyde thiosemicarbazone and some related compounds. Abstr. XIIth int. Congr. pure appl. Chem. p. 299.

Gangadharam, P. R. J., Harold, F. M. \& Schaefer, W. B. (1963). Selective inhibition of nucleic acid synthesis in Mycobacterium tuberculosis by isoniazid. Nature, Lond. 198, 712.

Koch-Weser, D., BARClay, W. R. \& EBerT, R. H. (1955). The influence of isoniazid and streptomycin on acid fastness, tetrazolium reduction, growth and survival of tubercle bacilli. Am. Rev. Tuberc. 71, 556.

KRÜGER-THIEMER, E. (1958). Isonicotinic acid hypothesis of the antituberculous action of isoniazid. Am. Rev. Tuberc. 77, 364.

Mackaness, G. B. \& SMITH, N. (1953). The bactericidal action of isoniazid, streptomycin and terramycin on extra cellular and intra cellular tubercle bacilli. Am. Rev. Tuberc. 67, 322.

MEaDow, P. (1956). The action of isonicotinic acid hydrazide on the metabolism of Mycobacterium smegmatis. J. gen. Microbiol. 14, 406.

Meadow, P. \& Knox, R. (1956). The effect of isonicotinic acid hydrazide on the oxidative metabolism of Mycobacterium tuberculosis var. bovis BCG. J. gen. Microbiol. 14, 414.

MidDlebrooK, G. (1952). Sterilization of tubercle bacilli by isonicotinic acid hydrazide and the incidence of variants resistant to the drug in vitro. Am. Rev. Tuberc. 65, 765.

Milner, H. W., Lawrence, N. S. \& French, C. S. (1950). Colloidal dispersion of chloroplast material. Science, N.Y. 111, 633.

Roberts, R. B., Abelson, P. H., Cowie, D. B., Bolton, E. T. \& Britten, R. J. (1955). Studies of biosynthesis in Escherichia coli. Publs Carnegie Instn, p. 607.

Schaefer, W. B. (1954). The effect of isoniazid on growing and resting tubercle bacilli. Am. Rev. Tuberc. 69, 125.

Schmidt, G. \& Thannhauser, S. J. (1945). A method for the determination of desoxyribonucleic acid, ribonucleic acid and phosphoproteins in animal tissue. J. biol. Chem. 161, 83.

Strickland, K. P., Thompson, R. H. S. \& Webster, G. R. (1956). The action of phosphatases of human brain on lipid phosphate esters. J. Neurol. Neurosurg. Psychiat. 19, 12.

Tsukamura, M. \& Mizuno, M. (1962). Mode of action of isoniazid viewed from isotope incorporation studies. Kekkaku 37, 29.

WINDER, F. C. \& DenNenY, J. M. (1957). The metabolism of inorganic polyphosphate in Mycobacteria. J. gen. Microbiol. 17, 573. 